\title{
Anthony KALDELLIS et Ioannis POLEMIS (éd.), Saints of Ninth-and Tenth-Century Greece
}

Michel Fauquier

\section{OpenEdition}

\section{Journals}

Édition électronique

URL : https://journals.openedition.org/ccm/5105

DOI : $10.4000 / \mathrm{ccm} .5105$

ISSN : 2119-1026

\section{Éditeur}

Centre d'études supérieures de civilisation médiévale/Université de Poitiers

\section{Édition imprimée}

Date de publication : 1 septembre 2020

Pagination : 192-194

ISBN : 978-2-490783-06-9

ISSN : 0007-9731

Référence électronique

Michel Fauquier, "Anthony kaldeluls et loannis polemis (éd.), Saints of Ninth-and Tenth-Century Greece», Cahiers de civilisation médiévale [En ligne], 250-251 | 2020, mis en ligne le 01 septembre 2020, consulté le 02 décembre 2022. URL : http://journals.openedition.org/ccm/5105; DOI : https://doi.org/10.4000/ ccm.5105

\section{(c) (i) (9)}

Creative Commons - Attribution - Pas d'Utilisation Commerciale - Pas de Modification 4.0 International - CC BY-NC-ND 4.0

https://creativecommons.org/licenses/by-nc-nd/4.0/ 
Saints of Ninth-and Tenth-Century Greece, A. Kaldellis et I. Polemis (éd.), Cambridge (Mass.)/Londres, Harvard University Press (Dumbarton Oaks Medieval Library, 54), 2019.

C'est toujours un très grand plaisir que de lire un nouveau volume de la prestigieuse édition de sources d'Harvard : plaisir des yeux que de parcourir un ouvrage à la présentation impeccable usant d'une police de caractères grecs de grande qualité; plaisir de l'esprit que de se nourrir de notices introductive (p. VII-XXIX : auteurs et œuvres) et conclusive (p. 309-312: histoire des sources utilisées), claires, précises et concises. Du fait de cette concision, on n'attendra toutefois pas des informations aussi fouillées que dans les éditions de la collection des « Sources chrétiennes » : le volume dû aux professeurs Anthony Kaldellis et Ioannis Polemis ne faisant que se conformer en cela aux normes de la Dumbarton Oaks Medieval Library, on ne pourra pas le leur reprocher.

Plus dommageable, l'apparat critique est un peu inégal : si les notes rejetées en fin d'introduction et en fin d'ouvrage ne souffrent aucune remarque - sinon à propos du mélange aléatoire de termes parfois transcrits du grec en grec-, on regrettera un index-prétexte qui ne sera pas d'une grande aide, et une bibliographie qui n'a pas jugé utile d'intégrer les références d'ouvrages permettant de contextualiser les œuvres étudiées. On ajoutera que cette bibliographie fait apparaître cruellement l'absence de toute production en langue française en ce domaine (une seule référence, fautive, dans les notes de fin d'ouvrage, à l'édition de la Vie de saint Théoclète dit de « Lacédémoine », alors qu'il s'agit bien évidemment de Lacédémone) : le cas n'étant pas isolé, cela devrait susciter une interrogation sur la place qu'on laisse aux études en langues anciennes dans les universités francophones en général, et françaises en particulier.

Le volume édité par les professeurs A. Kaldellis de l'Université d'État de l'Ohio, et I. Polemis de l'Université d'Athènes, regroupe six œuvres à caractère hagiographique bien que de genres différents : 
à côté de trois Vies (des saints Pierre d'Argos, Théoclète de Lacédémone et Théodore de Cythère), on trouve le récit du martyre de saint Nicolas le Jeune ainsi qu'un Encomium (Éloge) lui étant consacré, l'oraison funèbre de saint Athanase de Méthone (en Macédoine antique, proche de la capitale de Philippe II, Pella), et une $\mu v \eta ́ \mu \eta$ (Commémoration : texte recueilli dans un $\sigma v v \alpha \xi \alpha ́ p ı v$, collection de textes brefs sur des saints) de saint Arsène de Corfou.

Certaines de ces œuvres sont de style relevé, comme la Vie de saint Pierre d'Argos, d'inspiration néoplatonicienne, qui est due à Théodore de Nicée, un membre des cercles littéraires proches du basileus Constantin VII Porphyrogénète (945-959). Par contraste, l'oraison funèbre de saint Athanase de Méthone ainsi que les Vies des saints Théoclète de Lacédémone et Théodore de Cythère, sont des œuvres moins élaborées, rédigées par des érudits provinciaux à l'imitation de celles des grands lettrés, mais avec moins d'art.

Ce corpus comble un vide important, les $\mathrm{IX}^{\mathrm{e}}$ et $\mathrm{X}^{\mathrm{e}} \mathrm{s}$. grecs étant pauvres en sources, au point que, selon une habitude malheureusement assez répandue dans la production anglo-saxonne, d'aucuns se sont crus obligés de qualifier cette période de Dark Age, habitude avec laquelle les éditeurs prennent heureusement leur distance, préférant parler de Middle Ages, expression qui reste peu appropriée. Ils insistent au contraire, d'une part, sur le fait que la Vie de saint Pierre d'Argos offre un éclairage décisif sur l'autorité et l'assistance épiscopales à la charnière des $\mathrm{IX}^{\mathrm{e}}$ et $\mathrm{X}^{\mathrm{e}} \mathrm{s}$. (né et mort à une date inconnue, saint Pierre d'Argos a participé au synode réuni à Constantinople en 920) et, d'autre part, sur le caractère très précieux de la Vie de saint Théodore de Cythère, principale source d'époque byzantine sur cette île.

Le volume cinquante-quatrième de la Dumbarton Oaks Medieval Library s'ouvre sur le récit du martyre de saint Nicolas le Jeune (ou de Vounaine, en Thessalie, où il est réputé avoir subi le martyre), un ancien militaire ayant servi sous le règne du basileus Léon VI (886-912) avant de devenir ermite et d'être capturé puis mis à mort. Ce récit semble s'inspirer d'une tradition remontant au règne du basileus Léon III (717-741) quand les Arabes et les Bulgares - plutôt que les Avars mentionnés dans le texte - menaçaient les Balkans, et avant que ces derniers n'eurent adhéré au christianisme et pris Larissa en 986. L'Encomium consacré à ce même saint Nicolas le Jeune fut rédigé par un prêtre du nom d'Achaïkos, au plus tard au XII ${ }^{e} \mathrm{~s}$., après le récit de son martyre dont il s'inspire, et qui lui permet de le dater ainsi de façon approximative. Le choix de placer les faits sous le règne de Léon VI, et non sous celui de Léon III, aurait pu être motivé, selon les éditeurs, par la volonté de l'hagiographe de ne pas associer la mémoire du saint à celle d'un empereur qui lança la querelle iconoclaste : à vrai dire, l'argument a peu de consistance, plusieurs saints orientaux étant attestés à partir du moment où Léon III pencha pour l'iconoclasme, soit en 725 ou 726 (André de Crète), dont plusieurs engagés dans cette querelle contre l'empereur (Germain, patriarche de Constantinople, David et Constantin, Hypace et André, Eutyche, Procope le Décapolite et Basile). Par ailleurs, à part le fait d'avoir servi dans l'armée, donc le pouvoir, saint Nicolas n'a eu aucun rapport avec celui-ci et ne fut concerné ni de près ni de loin par la querelle iconoclaste, en marge de laquelle sa vie s'est déroulée.

Saint Athanase de Méthone était originaire de Catane en Sicile, d'où sa famille fut chassée par l'invasion arabe en $827 / 828$, avant de trouver refuge à Patras dans le Péloponnèse. Saint Athanase y entra dans un monastère, avant de devenir ermite, de retourner dans son monastère comme abbé, et d'être élu évêque de Méthone. Il mourut après 879 , date à laquelle sa présence est attestée à un concile. Son oraison funèbre fut rédigée par Pierre d'Argos, à partir d'une Vie plus ancienne. Ce Pierre d'Argos fut lui-même l'objet d'une Vie, rédigée par un de ses disciples, Théodore de Nicée. Pierre d'Argos était issu d'une famille aristocratique connue pour sa piété, dont le fils aîné, Paul devint disciple d'un ascète lui aussi prénommé Pierre, avant d'entraîner toute sa famille dans la vie monastique, dont le jeune Pierre d'Argos. Nicolas I ${ }^{\text {er }}$, patriarche de Constantinople (901/907912/925) appela Paul à la tête de l'évêché de Corinthe, et proposa l'épiscopat à son frère Pierre, mais celui-ci refusa. Néanmoins, à la mort de l'évêque d'Argos un peu après 912, les citoyens et son frère Paul le contraignirent à accepter la succession. Saint Pierre d'Argos mourut en 921/922.

Saint Théoclète commença sa vie religieuse comme ermite avant d'être élu contre son gré évêque de Lacédémone. Il est vraisemblablement le Théoclète de cette cité qui souscrivit les actes du quatrième concile de Constantinople (869/870), lequel condamna le laïc Photios dont le basileus Michel III (842-867), dit « L'Ivrogne », avait cru pouvoir faire un improbable patriarche de Constantinople en déposant Ignace, ce qui déclencha un schisme durable. La Vie de saint Théoclète fut composée à l'occasion de l'élection de Lacédémone en métropole en 1082.

Saint Théodore, né en Messénie, fut recueilli par un de ses parents prêtre quand il devint orphelin. Marié et ordonné diacre peu après $879 / 880$, il quitta 
sa famille pour devenir moine, se rendit en pèlerinage au tombeau de saint Pierre à Rome et finit sa vie dans l'île de Cythère en compagnie d'un moine du nom d'Antoine. La Vie qui est parvenue jusqu'à nous, composée par un certain Léon, est basée sur un texte plus ancien écrit après la libération de la Crète en 961. Cette Vie, dont l'aspect artificiel a frappé la critique semble avoir beaucoup emprunté à la vie d'un ascète lui aussi prénommé Théodore, et n'a pas dû être rédigée avant le début du $\mathrm{XI}^{\mathrm{e}} \mathrm{s}$.
Enfin, saint Arsène de Corfou est né au IX $\mathrm{X}^{\mathrm{e}} \mathrm{s}$. en Palestine. Il s'installa à Constantinople où il devint peut-être l'économe du patriarche Tryphon (928-931), avant d'être porté sur le siège épiscopal de Corfou en 933, où il fut fait prisonnier par d'improbables « Scythes ».
Michel FAUQUIER UMR 7302 - CESCM Université de Poitiers 